Sir,

\section{Sebaceous gland carcinoma of the eyelid seventeen years after irradiation for bilateral retinoblastoma} Sebaceous gland carcinoma has a peak incidence in the sixth to seventh decade of life. The occurrence of this malignant neoplasm of the eyelids in adolescence is exceptionally rare and, to our knowledge, has been described only in patients after irradiation, usually for heritable retinoblastoma. ${ }^{1}$ We report a case of sebaceous gland carcinoma in a teenager and stress the need for vigilance in following patients with heritable retinoblastoma for second malignant neoplasms.

\section{Case report}

A 17-year-old white male presented to the Ocular Oncology Service of the Wills Eye Hospital with a 3 year history of a recurrent 'stye' on his right upper eyelid (Fig. 1). This had fluctuated in size, and a recent haemorrhage prompted him to seek medical attention. He had a history of bilateral sporadic retinoblastoma, diagnosed at the age of 4 months. At that time the left eye was enucleated and the right eye was managed with sequential photocoagulation, cryotherapy and external beam irradiation (4600 rads). The right eye subsequently developed cataract; following cataract surgery his vision was $6 / 12$.

External examination disclosed slight thickening and telangiectasia of the tarsal conjunctiva at the margin of the middle third of the right upper eyelid. The eyelid margin was irregular and friable. The meibomian gland orifices appeared normal. There was no palpable eyelid mass nor facial lymphadenopathy. An incisional biopsy was performed on the tarsal conjunctiva and simultaneous staging biopsies of the bulbar, forniceal and tarsal conjunctiva showed the disease to be limited

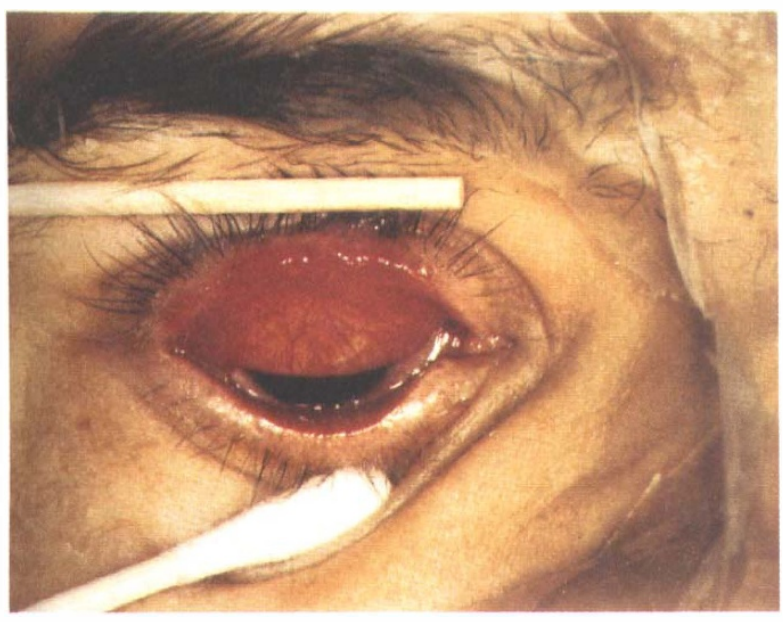

Fig. 1. Clinical photograph showing irregular thickening of the margin of the right upper eyelid. to the adjacent superior palpebral conjunctiva. Histopathological examination revealed lobules of tumour cells with foamy, vacuolated cytoplasm that was oil red $\mathrm{O}$ positive, consistent with sebaceous gland carcinoma (Fig. 2). Full-thickness eyelid resection with excisional biopsy of the tumour and conjunctival cryotherapy was performed. His post-operative course was uneventful with no recurrence noted at a 3 month follow-up appointment.

\section{Comment}

The mutagenic effects of radiation are well known and there have been isolated reports of cutaneous malignancy following periocular irradiation for benign conditions such as acne or facial hemangiomas. ${ }^{1,2}$ The increased risk of second malignancies in bilateral retinoblastoma is well established, with reported incidence rates varying from $19 \%$ to $90 \%$ at 30 years following diagnosis of retinoblastoma. ${ }^{3-5}$ Radiation appears to increase the risk and it has been postulated that radiation may exert this effect by causing damage to the remaining functional copy of the retinoblastoma gene. ${ }^{6}$ The types of second tumour include sarcoma, particularly osteosarcoma, cutaneous melanoma and sebaceous gland carcinoma. ${ }^{7}$

Sebaceous gland carcinoma is a relatively rare malignancy accounting for $5 \%$ of malignant eyelid tumours. ${ }^{8}$ It has also been described in the eyebrow, caruncle and conjunctiva. Sebaceous gland carcinoma most commonly affects the upper eyelid, typically as a solitary chalazion-like nodule, but occasionally presents with intraepithelial tumour that can mimic chronic blepharitis. For these reasons diagnosis is often delayed and this in part accounts for the significant mortality reported in some series ( $22 \%$ at 5 years). ${ }^{9}$ Sebaceous

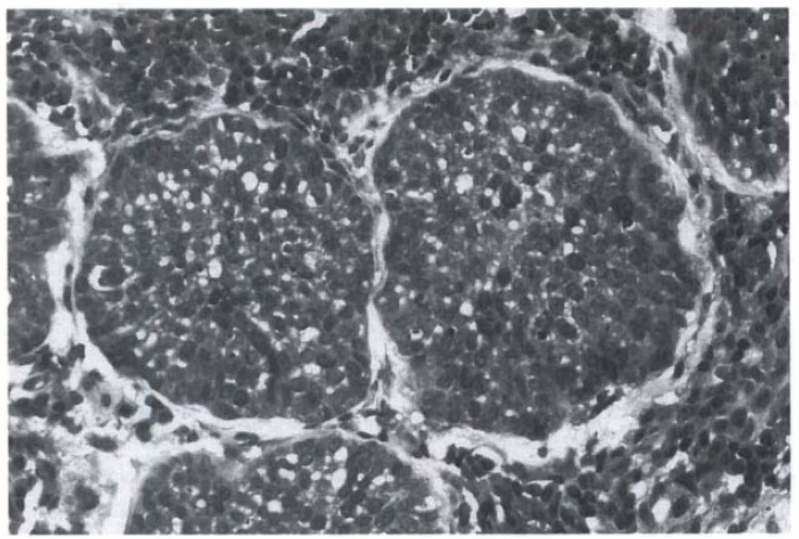

Fig. 2. Photomicrograph of the eyelid biopsy showng lobules of tissue with cells exhibiting foamy cytoplasm consistent with sebaceous gland carcinoma (haematoxylin $\mathcal{E}$ eosin, $\times 100$ ). 
gland carcinoma almost invariably occurs in elderly patients and it is exceptionally rare under the age of 40 years. There have been a small number of cases reported in adolescent survivors of bilateral retinoblastoma, especially those treated with external beam radiotherapy. 3,7

This case is important for two reasons. First, it highlights the risk of second malignancies in survivors of hereditary retinoblastoma, particularly in those treated with external beam irradiation. In this case the second tumour developed 17 years after radiation. Second, such tumours may occur at an earlier age than would be expected and indeed may mimic benign conditions. We recommend that ophthalmologists be aware of the possibility of sebaceous gland carcinoma when examining survivors of bilateral retinoblastoma with a putative diagnosis of chalazion or blepharitis.

Support was provided by the International Award of Merit in Retina Research, Houston, Texas (J.A.S.); Lions Eye Bank, Philadelphia, PA (C.L.S., J.A.S.); Macula Foundation (C.L.S.); Eye Tumour Research Foundation, Philadelphia, PA (C.L.S., J.A.S.); Westminster Medical Practice Ophthalmic Scholarship, Belfast (P.R.); and the Noel and Sara Simmonds Endowment for Ophthalmic Pathology, Wills Eye Hospital (R.C.E.).

\section{References}

1. Khan JA, Grove AS, Joseph MP, Goodman M. Sebaceous carcinoma: diuretic use, lacrimal system spread, and surgical margins. Ophthalmic Plast Reconstr Surg 1989;5:227-34.

2. Schlernitzauer DA, Font RL. Sebaceous gland carcinoma of the eyelid. Arch Ophthalmol 1976;94:1523-5.

3. Roarty JD, McLean IW, Zimmerman LE. Incidence of second neoplasms in patients with bilateral retinoblastoma. Ophthalmology 1988;95:1583-7.

4. Moll AC, Imhof SM, Bouter LM, Kuik DJ, Den Otter W, Bezemer PD, Koten JW, Tan KE. Second primary tumours in patients with hereditary retinoblastoma: a register-based follow-up study, 1945-94. Int Cancer 1996;67:515-9.

5. Abramson DH, Ellsworth RM, Kitchin FD, Tung G. Second non-ocular tumours in retinoblastoma survivors. Are they radiation-induced? Ophthalmology 1984;91:1351-5.

6. Howrey RP, Lipham WJ, Schultz WH, Buckley EG, Dutton JJ, Klintworth GK, Rosoff PM. Sebaceous gland carcinoma: a subtle second malignancy following radiation therapy in patients with bilateral retinoblastoma. Cancer 1998;83:767-71.

7. Weichselbaum RR, Beckett MA, Diamond AA. An important step in carcinogenesis may be inactivation of cellular genes. Int J Radiat Oncol Biol Phys 1989;16:277-82.

8. Doxanas MT, Green WR. Sebaceous gland carcinoma: a review of 40 cases. Arch Ophthalmol 1984;102:245-9.

9. Rao NA, Hidayat AA, McLean IW, Zimmerman LE. Sebaceous carcinomas of the ocular adnexa: a clinicopathologic study of 104 cases, with 5 year follow-up data. Hum Pathol 1982;13:113-22.

\footnotetext{
Paul Rundle ${ }^{1}$

Jerry A. Shields ${ }^{1}$

Carol L. Shields ${ }^{1}$

Ralph C. Eagle $\mathrm{Jr}^{2}$

Arun D. Singh ${ }^{1}$

${ }^{1}$ Oncology Service

${ }^{2}$ Pathology Department

Wills Eye Hospital

Thomas Jefferson University

Philadelphia, USA
}

Jerry A. Shields, MD

Oncology Service

Wills Eye Hospital

900 Walnut Street

Philadelphia, PA 19107-5598, USA

Sir,

Use of ganciclovir implants for CMV retinitis in an 18month-old child with AIDS

Cytomegalovirus (CMV) retinitis may not present until the vision is significantly impaired in a very young patient, as a recent letter to Eye has illustrated. ${ }^{1}$ The patient described in this case report was found on screening to have bilateral CMV retinitis as an AIDSdefining event at 18 months of age. Ganciclovir implants contained his disease and allowed him to come off intravenous therapy. He is the youngest ever recipient of this treatment.

\section{Case report}

A male child born in the UK of African parentage was first diagnosed as being HIV positive at the age of 12 months, having been admitted to the paediatric infectious diseases unit at St George's Hospital at 11 months suffering from lobar pneumonia.

Six months later he was included in an ophthalmological screening programme for HIV-positive children and found to have bilateral CMV retinitis. Because of the position of the disease in both eyes (juxtapapillary in the left and immediately adjacent to the fovea in the right), there was no room for 'edge creep' with delayed treatment or reactivation.

Treatment was initiated with intravenous ganciclovir at induction dosage for 3 weeks and reduced to maintenance dosage (once daily for 5 days in 7), which contained the disease but had to be discontinued after 6 months due to bone marrow suppression.

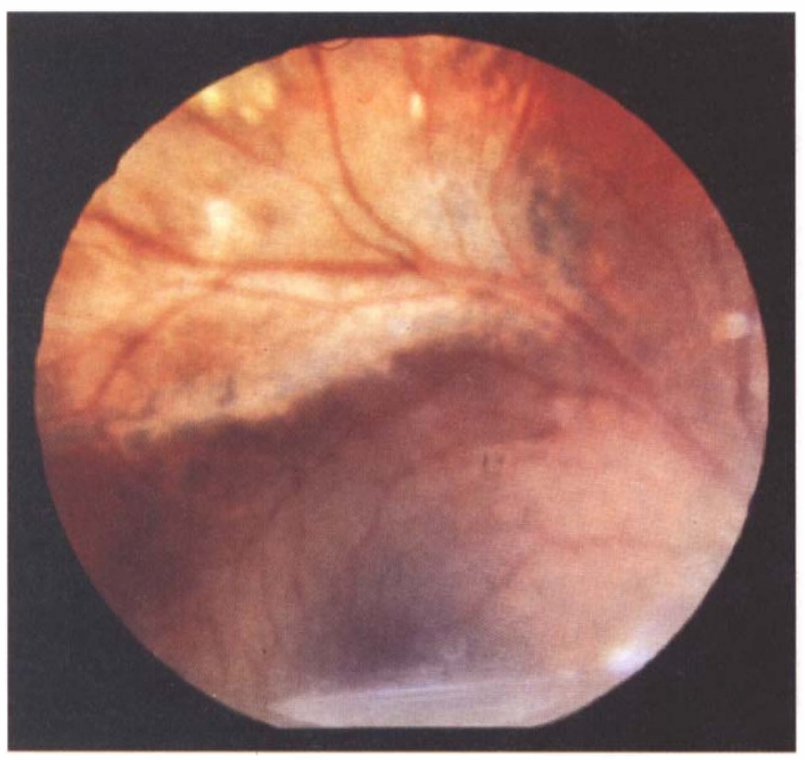

Fig. 1. Right eye: CMV retinitis adjacent to the fovea superiorly. 